\title{
El Partido Comunista de Chile y los pueblos indígenas entre 1912 y 1973: continuidades y cambios en el discurso
}

The Communist Party of Chile and indigenous peoples between 1912 and 1973: continuities and changes in discourse

José Miguel Urzúa*

Resumen: El presente artículo expone los resultados y conclusiones del estudio de la relación entre las concepciones que se elaboraron desde PC de Chile respecto a los pueblos indígenas, en especial, el mapuche. A través de una revisión hemerográfica, identifica y analiza cuales fueron los discursos establecidos por el PC; con el propósito de constatar la hipótesis respecto la elaboración de distintos discursos inclusivos para comprender la existencia y participación política de los diferentes pueblos indígenas, desde 1912 hasta 1973.

Palabras clave: partido comunista chile, pueblo indígena, participación política, mapuche, clase social.

Abstract: This paper presents the results and conclusions of the study of the relationship between the ideas that were elaborated from PC of Chile with respect to the indigenous peoples, especially Mapuche. Through a hemographic review, it identifies and analyzes the discourses established by the PC; with the purpose of verifying the hypothesis regarding the elaboration of different inclusive speeches to understand the existence and political participation of the different indigenous peoples, from 1912 to 1973.

Keywords: chilean communist party, indigenous people, political participation, mapuche, social class.

Recibido: 14 junio 2019 Aceptado: 22 septiembre 2019

* Chileno, Doctor en Antropología Universidad de Barcelona, adscrito al Grupo de Investigaciones en Economía y Ciencias sociales (GICSEC) e investigador asociado al Programa de antropología jurídica (PRANJU) de la Facultad de derecho de la Universidad de Chile. El presente artículo es un resumen, adecuación y actualización de la tesis de grado para optar al grado de Antropólogo (Universidad Academia de Humanismo Cristiano, 2007). Dirección de correo electrónico: josemiguelurzua@gmail.com 


\section{Introducción}

La tesis habitualmente esgrimida para criticar la praxis $^{1}$ desplegada desde la izquierda chilena hacia los pueblos indígenas, se basa fundamentalmente en la certeza respecto de la manipulación política perpetrada por las agrupaciones marxistas, ejecutada con el propósito de asimilar a dichas poblaciones indígenas a la sociedad nacional, de acuerdo a una incomprensión de sus características culturales específicas y producto de una visión materialista determinista y unilateral ${ }^{2}$. Esta investigación, pone en duda parcialmente dicha tesis a partir de la evidencia recabada. La hipótesis principal que guio esta investigación, fue la premisa concerniente a la existencia efectiva de discursos inclusivos, diseñados por el Partido Comunista de Chile para integrar a los indígenas a la sociedad chilena, puesto que estimaba que dichos grupos pertenecían a un grupo más amplio de individuos sujetos a condiciones de explotación (proletarios, campesinos, etc.). Sin embargo, al vapor del análisis de la prensa del partido acerca de la cuestión indígena y el estudio de su historia, no es posible plantear la presencia de una exclusiva lógica aglutinadora y homogénea; por el contrario, es posible argumentar la presencia de "discursos" y no tal sólo de un "discurso" único y definitivo 3 . Por medio de la comprensión de la trayectoria del PC a través de etapas históricas reflejadas en sus medios de comunicación, es verosímil el hallazgo de diferentes posturas y acercamientos a la problemática de los pueblos indígenas.

Las críticas al PC en torno a esta problemática fueron numerosas; ellas apuntaron principalmente a denunciar al marxismo como una teoría que englobó en una categoría homogénea a los sectores explotados y en el caso de los pueblos indígenas, sometiéndolos de manera simplista mediante la noción "campesinos" para asimilarlos. Esto se puede atribuir al hecho que la interpretación comunista acerca de las realidades sociales, habría puesto acento exclusivamente en la supremacía de las relaciones sociales de producción por sobre las otras relaciones sociales no económicas. No obstante, a esas críticas, se puede oponer que el PC en determinados períodos históricos, sobre todo en la proclamación de la “República Autónoma Araucana” (1934) y en la proclamación de la ley indígena de 17.729

1 “En la primera tesis sobre Feuerbach, Marx define la praxis como actividad práctico-crítica, esto es una actividad humana sensible en la cual se resuelve lo real concebido subjetivamente". Gustavo Gozzi, "Praxis", Norberto Bobbio, Nicola Matteucci y Gianfranco Pasquino (eds.), Diccionario de política L-Z, Ciudad de México, SXXI Editores, 1261.

2 José Bengoa, "La cuestión indígena y la situación de las minorías étnicas”, Proposiciones 18, Santiago, Sur, enero 1990, p. 121-139; Antonio Melis, Diccionario histórico-crítico del marxismo, Berlìn, Instituto de Teoría Crítica de Berlín, 2004. Disponible en http:/ / dhcm.inkrit.org/cuestion-del-indio; Francisco Albizú Labbé, “El indigenismo de la Unidad Popular (Chile 1970-1973). Estado y Nación entre reformismo y realidad", Amérique Latine Histoire et Mémoire. Les Cahiers ALHIM [En línea], 28 | 2014, Publicado el 05 diciembre 2014- Disponible en: http://journals.openedition.org/alhim/5116; Guillaume Boccara, “Antropología diacrónica. Dinámicas culturales, procesos históricos y poder político", Boccara, G. y Galindo, S. (editores). Lógica mestiza en América. Temuco, Instituto de Estudios Indígenas/Universidad de La Frontera, 1999, 25.

3 Debido a la gran cantidad de posturas y definiciones sobre el concepto "discurso", se utilizará de manera operatoria el concepto concebido como "... toda práctica enunciativa considerada en función de sus condiciones sociales de producción, que son fundamentalmente condiciones institucionales, ideológico-culturales e histórico-coyunturales" en Gilberto Giménez, Poder, Estado y discurso. Perspectiva social y semiológica del discurso político-jurídico, Ciudad de México, Instituto de Investigaciones Jurídicas-Universidad Nacional Autónoma de México, 1981, 124. 
de la UP (1972), intentó aportar, dentro de este proceso para la "liberación de los indígenas", la idea de que explotación material tenía una coexistencia simultánea con la dominación política y cultural. En este contexto, se puede sostener que la concepción por parte del PC respecto a la existencia de los pueblos indígenas, estuvo mediada por la presencia de una tensión entre tres aspectos fundamentales: la condición del indígena como un sujeto explotado, la especificidad étnica y cultural del indígena y, por último, la superación de las condiciones de explotación bajo un proyecto único. Estos tres factores fueron articuladores de diferentes reflexiones acerca de esta problemática, generalmente de forma intermitente, condicionadas y tensionadas por las distintas etapas históricas por las cuales el PC transitó.

Es por eso, que se puede cuestionar la afirmación acerca de la posible utilización que habría hecho el comunismo chileno, y la izquierda en general, del desempeño indígena en política. Asumir la tesis de la manipulación comunista, implica concebir al indígena como un sujeto que fue susceptible de control y dispuesto a recibir órdenes externas. Este tipo de pensamiento minusvalora a los indígenas, situándolos como meros receptores de políticas elaboradas externamente, negando su capacidad de agencia y autonomía política ${ }^{4}$.

Otro elemento sustancial dentro de la problemática de la comprensión comunista de la cuestión indígena, fue la forma en que el PC de Chile interpretó las sugerencias externas producidas por el Movimiento Comunista Internacional (MCI), en particular, de la sede sudamericana de la Internacional Comunista (Komintern). De una u otra manera, el PC, tuvo que adecuar su política nacional a las recomendaciones provenientes desde el exterior puesto que, en aquella época, el MCI proponía lineamientos a todos los partidos comunistas del mundo. La política del PC hacia el indígena no careció de lo descrito anteriormente. Como se expondrá en adelante, el PC estuvo muchas veces influenciado exteriormente por el MCI, sobre todo, por el Bureau Sudamericano, en cuanto a la interpretación de la realidad indígena. Sin embargo, ello no sugiere una manipulación del MCI al PC, sino más bien, la capacidad interpretativa de los/as comunistas chilenos/as respecto de la coyuntura nacional e internacional ${ }^{5}$.

Fue escogida como fecha de inicio de la investigación, el origen y formación del Partido Comunista en 1912 (en esa época POS) ${ }^{6}$ puesto que marcó el comienzo de la conformación de una incipiente organización obrera, que se tradujo, por ejemplo, en la transformación de la Federación Obrera de Chile (FOCH) en una central clasista y de mayor radicalización 7 . Se consideró como fecha que pone término a este período de estudio, el derrocamiento del Gobierno de la Unidad Popular acaecido el año 1973, pues constituye un período que transformó sustancialmente las relaciones políticas y sociales entre los distintos sectores, y en general de toda la sociedad chilena.

\footnotetext{
4 Sergio Caniuqueo, "Siglo XX en el Gulumapu: de la fragmentación del Wallmapu a la Unidad Nacional Mapuche. 1880 a 1978”, Pablo Marimán, Sergio Caniuqueo, José Millalén y Rodrigo Levil, j ... Escucha, winka .. .! Cuatro ensayos de Historia Nacional Mapuche y un epílogo sobre el futuro, Santiago, LOM Ediciones, 2006.

5 Olga Ulianova, "Primeros Contactos entre el Partido Comunista de Chile y Komintern", Cuadernos de Historia número 18, Santiago, Departamento de Ciencias Históricas de la Universidad de Chile, diciembre 1998.

${ }_{6}^{6}$ El Partido Comunista de Chile tiene sus inicios en el Partido Obrero Socialista (POS), organizado en 1912 por Luis Emilio Recabarren. El cambio de nombre ocurrió durante el III Congreso llevado a cabo en 1922, en cual se unen a la Internacional Comunista.

7 Jorge Barría, El movimiento obrero en Chile, Santiago, Ediciones de la Universidad Técnica del Estado, 1971.
} 


\section{Discusión teórica}

La teoría marxista latinoamericana desarrollada para abordar la cuestión étniconacional durante el período que abarca esta investigación, fue variada y con posiciones dispares entre los/as autores/as. La situación descrita fue producto de dos elementos convergentes: por un lado, la influencia de la obra de Marx y Engels y, por otro, las circunstancias y particularidades propias de América Latina ${ }^{8}$. La obra de Marx y Engels tuvo posturas variantes en distintos momentos históricos, a raíz de las fuentes originarias del marxismo (liberalismo inglés, filosofía alemana y socialismo francés) y de las diferentes coyunturas históricas que experimentaron estos pensadores alemanes ${ }^{9}$. La separación en etapas y el papel del historicismo en los fundadores del marxismo, no estuvieron exentos de polémicas importantes ${ }^{10}$, sin embargo, es útil para los propósitos de esta investigación demarcar las diferentes posturas que se esgrimieron para comprender el papel civilizatorio de Europa, la cuestión nacional y el avance del colonialismo. Según Scaron, la obra de Marx y Engels atravesó por cuatro periodos respecto de la interpretación del problema nacional, y específicamente respecto la expansión de Occidente hacia países fuera de Europa, lo cual coincidió plenamente con sus posturas frente a los procesos acontecidos en América Latina ${ }^{11}$. Lo descrito, sin duda, derivó en repercusiones posteriores de divergencia entre sus discípulos/as. Prueba de ello, por ejemplo, son las discrepancias entre Lenin y Luxemburgo respecto el papel del proletariado polaco y el imperio zarista ${ }^{12}$.

En el discurso del marxismo clásico, fue la clase obrera el principal actor social generador de cambios en la sociedad. La hegemonía del proletariado fue dada, según el marxismo, por el hecho de que había predominancia del desarrollo urbano, industrial y moderno por sobre el sector agrario en los países adelantados de la época, como Inglaterra. Esta argumentación podría ser concebida como eurocentrista, de acuerdo a la disposición de los parámetros provenientes de Europa, como paradigma civilizatorio. Empero, a pesar de considerar, a las sociedades industrializadas de Europa occidental como los principales

8 Adolfo Sánchez, “El marxismo en América Latina”, Dialéctica, nº 19, 1988.

9 Vladimir Ilich Lenin: “Tres fuentes y las partes integrantes del marxismo", marzo de 1913, Vladimir Ilich Lenin, Obras, Tomo V (1913-1916), Moscú, Edición Progreso, 1973.

10 Louis Althusser, La revolución teórica de Marx, Ciudad de México, Siglo XXI Editores, 1967; Edward P. Thompson, La miseria de la teoría, Barcelona, Crítica, 1981.

11 En la primera (1847-1856), armonizan el rechazo moral a las implicaciones del colonialismo mediante una relativa apología intelectual de sus consecuencias "civilizadoras". La segunda (1856-1864) se trata de una fase de mudanza que se destaca por una actividad periodística intensa marcada por la denuncia informativa de las atrocidades del avance de las potencias colonizadoras. La tercera (1864-1883) marca la fundación de la Internacional y la asimilación del internacionalismo proletario anticolonial, lo cual queda plasmado en la postura de Marx frente a la liberación nacional de Irlanda respecto Inglaterra y el subdesarrollo de la India provocado por el mismo país anglosajón, por ejemplo. La última y cuarta etapa (1883-1895), se extiende desde la muerte del pensador renano hasta el óbito de su colaborador. Esta etapa se caracteriza por un estancamiento del pensamiento de Engels en relación con el interés por los países fuera de la órbita capitalista central, e incluso se acerca a algunas posiciones patrióticas en relación con el conflicto entre Alemania y Rusia/Francia. Pedro Scaron, “Introducción”, Karl Marx y Friedrich Engels, Materiales para la historia de América Latina, Córdoba, Cuadernos de Pasado y Presente 30, 1972.

12 Héctor Díaz-Polanco, "Etnia, clase y cuestión nacional”, Cuadernos Políticos, número 30, Ciudad de México, editorial Era, octubre-diciembre de 1981, pp. 53-65. 
escenarios para la constitución de sociedades socialistas, los procesos revolucionarios que triunfaron, provinieron de países agrarios como Rusia, China, Cuba o Vietnam, lo cual implicó nuevas reflexiones en torno al papel del campesinado ${ }^{13}$.

Además, se hizo consciente en los/ as intelectuales del llamado “Tercer Mundo", que la situación de explotación y pobreza en que vivían, era producto de la imposición de un contexto social de dominación creado desde Europa, lo cual implicaba la descolonización entendida en amplio sentido, no exenta de violencia ${ }^{14}$.

Esta fue la forma por la cual distintos países periféricos, con sus distintas especificidades, forjaron identidades mediadas por elementos originarios de distintas fuentes. En Latinoamérica las preguntas principales fueron: a) ¿América latina era una "extensión de Europa" anclada en un territorio plagado de barbarie la cual tenía que ser civilizada? ${ }^{15}$ y b) ¿la identidad latinoamericana fue producto de una composición de varios factores (indígenas, afroamericanos y europeos), absorbidas por la civilización burguesa procedente de Europa, y mantenidas por la sociedad capitalista bajo su hegemonía, como identidades subyacentes y negadas?16.

Dentro del marxismo de los países periféricos, estas polémicas provocaron preguntas en torno al efectivo quiebre del marxismo respecto a la civilización burguesa: ¿Marx, en conjunto con Engels, efectivamente realizaron un rompimiento definitivo con el proyecto liberal?17. Una de las salidas a este cuestionamiento tendió a aceptar al proyecto burgués como la antesala modernizadora y urbana, necesaria para la consecución del proyecto comunista. También, los pactos con la burguesía democrática fue una plataforma de oposición al avance del fascismo internacional, como ocurrió con la participación de los partidos comunistas en los frentes populares. Entonces, perfectamente, podría sostenerse que el comunismo pretendió ser la superación simple y la etapa superior, de un modo de producción en decadencia. En este caso, no existiría un quiebre con el pensamiento burgués ya que el marxismo como producto de un momento histórico determinado no pudo prorrumpir los márgenes del contexto histórico y las influencias que le sirvieron de base.

Sin embargo, existió en Marx el afán de llevar a cabo un proyecto social diferente a todos los proyectos anteriores. Por consiguiente, el proyecto comunista aglutinaría las contradicciones anteriores, intentando superarlas. Por ello, y así lo demostró Wolf18, Marx en su última época, desarrolló un pensamiento evolutivo multilineal. Esto acaeció por el "descubrimiento" de Marx de las sociedades caracterizadas por poseer un sistema políticoeconómico denominado "modo de producción asiático", el cual existió simultáneamente al feudalismo en Europa. Según Marx, estas sociedades no se desviaron del sendero del progreso, sino que más bien pudieron desarrollar sistemas diferentes que no necesariamente

13 Eric Wolf, Las luchas campesinas en el s. XX, Madrid, Siglo XXI, 1972.

14 Frantz Fanon, Los condenados de la tierra, Ciudad de México, 1983.

15 Héctor Nahuelpán, "El sueño de la identidad latinoamericana o la búsqueda de lo propio en lo ajeno", Atenea n.495, Concepción, 2007.

16 Guillermo Bonfil Batalla, México Profundo, una civilización negada, Ciudad de México, Grijalbo, 1987.

17 Augusto Samaniego y Carlos Ruiz, “Comunidad agraria y autonomías para el pueblo mapuche (1953-1972). Lipschutz y el hombre progresista: ¿Un marxismo liberal o innovador?", Revista de Historia Social y de las mentalidades" La construcción histórica del socialismo en Chile, Año VII, Volumen 2, Santiago, USACH, 2003.

18 Eric Wolf, Europa y la gente sin historia, Ciudad de México, FCE, 1987 
arribaron al modo de producción capitalista. Este pensamiento, abrió nuevas perspectivas en cuanto a la existencia de diversas formas de conformar una formación económica-social, puesto que desconoció el carácter inevitable del desarrollo que contemplaba la fase capitalista. Debido a estos antecedentes, se levantaron arduos debates en torno a los proyectos socialistas en sociedades agrarias como Rusia, China, Vietnam o Cuba, sin duda, paradigmas revolucionarios en el período de descripción ${ }^{19}$.

En el caso de la argumentación teórica marxista concerniente a la cuestión étniconacional, elaborada desde Latinoamérica, destacan tres autores importantes: Vicente Lombardo, José Carlos Mariátegui y Alejandro Lipschutz.

En México, Lombardo intentó aplicar los métodos analíticos de Marx para comprender mecanismos de liberación para las masas indígenas expoliadas en latifundios y fábricas. Para este pensador marxista, que asumió la visión estalinista sobre las aglomeraciones étnicas ${ }^{20}$, los grupos étnicos mexicanos fueron nacionalidades oprimidas que debieron participar activamente en su emancipación y en su inserción dentro del ambiente político mexicano. Formuló como una medida de solución a la cuestión indígena, la proletarización creciente de los indígenas en grandes industrias y la autonomía política absoluta de las entidades pobladas por los indígenas ${ }^{21}$. Lombardo puede ser catalogado como indigenista, en la medida que, afirmó la integración del indígena a la sociedad nacional, por medio de la participación laboral en las fábricas como obrero. Marzal expone sobre Lombardo que: “... después del inicial análisis de las etnias con las nacionalidades oprimidas, no difirió mucho de la alternativa oficial, por aceptar la integración y aun la proletarización del indio en la sociedad nacional mestiza" 22 .

En Perú, Mariátegui aplicó a la historia de su país, los esquemas marxistas de evolución económica. Para él, el gobierno colonial español no ejecutó una real colonización en el Perú, debido a la escuálida cantidad de colonizadores que arribaron, ni tampoco una creación económica concreta, con excepción de la orden jesuita. Por tanto, el aparato productivo estuvo compuesto por fuerza de trabajo esclavo de origen africano para las haciendas e indígena para las mitas mineras. La independencia marcó la inserción de la burguesía dentro del proceso, empero, no influyó en una revolución antifuedal; por el contrario, generó una alianza entre la burguesía comercial y la aristocracia propietaria, que detentaba grandes porciones de tierras en las haciendas serranas. Mariátegui sostuvo que: "Todas las tesis sobre el problema indígena que ignoran o eluden a éste como un problema económico-social, son otros tantos estériles ejercicios teoréticos y a veces no solo verbales, condenados a un absoluto descrédito" 23 . Partiendo de este análisis, planteó medidas de solución: adjudicación de los latifundios serranos a las comunidades, transformación de las comunidades en cooperativas de producción, apoyo a la lucha política de los "yanacones" contra los hacendados y, por último, educación político-ideológica de las masas indígenas.

\footnotetext{
19 Maurice Godelier, "Modo de producción asiático y los esquemas marxistas de evolución de las sociedades", Godelier, M., Marx, K. y Engels, F., Sobre el modo de producción asiático, Barcelona, Martínez Roca, 1972

20 Jose Stalin, El Marxismo y la cuestión nacional, Barcelona, Anagrama, 1977.

21 Vicente Lombardo Toledano, El problema indígena, Ciudad de México, Sep-Setenta, 1973.

22 Marzal, Manuel, Historia de la Antropología Volumen I Primera parte: Antropología Indigenista, Quito, Abya-Yala, en coedición con Universidad Politécnica Salesiana, 1998, 453.

23, José Carlos Mariátegui, 7 ensayos sobre la realidad peruana, Lima, Biblioteca Amauta, 1976, 35.
} 
Dentro de este contexto, Mariátegui no apreciaba a los pueblos indígenas como nacionalidades, alejándose así de las directrices del $\mathrm{MCI} 24$.

En Chile, podemos destacar al militante del PC y polímata, Alejandro Lipschutz ${ }^{25}$. Fue uno de los primeros antropólogos que cuestionó el concepto de raza ${ }^{26}$, planteó algunas tesis con respecto a la propiedad indígena ${ }^{27}$, señaló algunas ideas en torno al tema de la autonomía ${ }^{28}$ y colaboró como perito antropológico en una causa que buscaba inculpar a una mujer mapuche de asesinato, mediante la defensa del derecho consuetudinario mapuche como un sistema jurídico pertinente y adecuado ${ }^{29}$. Lipschutz rescató creativamente la propuesta leninista guiada por la intención de beneficiar el derecho de las naciones a la autodeterminación ${ }^{30}$, pues para él, en la Unión Soviética, distintos grupos étnicos y nacionales coexistieron sin conflictos, por medio de la instauración de un régimen social y cultural basado en la distribución equitativa de las riquezas. Lipschutz criticó al indigenismo porque estaba compuesto de elementos asimilacionistas, desarrollistas y etnocentristas, y lo consideró como justificación al atropello de las diferentes culturas.

El concepto de clase social en relación con la cuestión nacional, dentro del marxismo latinoamericano, estuvo lejos de concordar una recapitulación definitiva. En síntesis, es posible definir tres posturas marxistas principales sobre la cuestión de las nacionalidades dentro del contexto de la lucha de clases: a) la posición estalinista (Lombardo) que apuntó la relevancia de la condición objetiva de los diferentes grupos, la cual determinaba las características culturales y económicas de dichos grupos. Esta postura concibió a los grupos indígenas como nacionalidades, las cuales debieron asimilarse a la sociedad del EstadoNación correspondiente, por medio de la proletarización, en virtud de desarrollar la capacidad productiva de la industria nacional 31 , b) la posición mariateguista estableció que los indígenas pertenecían a estructuras socio-económicas, en las cuales fueron sometidos a condiciones de explotación. De esta manera, no constituían per se una nacionalidad, sino más bien, pertenecían a grupos más amplios de personas. Estableció que la posibilidad de liberar a los indígenas de las condiciones de explotación, fue la abolición del sistema gamonalista al cual calificó de "feudal" y c) la posición de Lipschutz que planteó que las agrupaciones indígenas constituían nacionalidades dominadas, las cuales yacían en estructuras socio-económicas opresivas. Lipschutz propuso que los grupos étnicos pudieron

24 Marc Becker, “Mariátegui y el problema de las razas en América Latina”, en Revista Andina 35, 2002.

25 Bernardo Berdichewsky. "La Visión Crítica de Lipschutz de la Antropología Moderna”, IV Congreso Chileno de Antropología, Santiago de Chile, Colegio de Antropólogos de Chile A. G., 2001.

26 Alejandro Lipschutz, El problema racial en la conquista de América y el mestizaje, Santiago, Editorial Andrés Bello, 1967.

27 Alejandro Lipschutz, La comunidad indígena en América y en Chile, Santiago, Editorial Universitaria, 1956.

28 Alejandro Lipschutz, "El régimen social de la URSS y su importancia para Hispanoamérica”, Aurora, Segunda Época, N 1, Santiago, Chile, 1964.

29 Juan C. Skewes, “Lipschutz, la bruja y la escena colonial”, Pablo Neruda, Volodia Teitelboim, Oiga Poblete, Bernardo Berdichewsky, Zenta Kimene y Peter Krupnikov, José Manuel Lira, Roberto Morales y Juan Carlos Skewes, Alejandro Lipschutz Nueva Antología, CNCA-ICAL, Santiago, 2005.

30 Vladimir Ilich Lenin, "El derecho de las naciones a la autodeterminación", Vladimir Ilich Lenin, Obras complaetas, Tomo XXI, Madrid, Akal, 1977.

31 Dentro de esta postura también pueden ser señalados Ricardo Pozas e Isabel Horcasitas, Los indios en las clases sociales de México, La Habana, Casa de las Américas, 1971. 
haber conformado repúblicas autónomas en virtud de que hubiesen podido autodeterminarse sociopoliticamente. Sin embargo, expresó que era necesario primero la abolición de las relaciones sociales de producción del sistema capitalista de la sociedad en su conjunto, para que así hubiesen podido conformar dichos Estados. Según Samaniego y Ruiz, Lipschutz, por lo menos desde los 60, fue promotor intelectual de las autonomías indígenas, las cuales fueron truncadas por el golpe y la dictadura cívico-militar ${ }^{32}$.

En cuanto al caso chileno en específico, existe bibliografía significativa que abordó la situación en varias regiones y pueblos indígenas del país. Respecto de los aymaras en el ciclo salitrero, González sugiere que el paradigma concentrado en la clase social de las organizaciones pampinas, encubrió a la población indígena de las salitreras, la cual se integró a dicho paradigma. Inclusive, asegura que cuando existió colisión entre la visión obrerista y la étnica, la última "fue duramente reprimida: como la crítica obrera a los indígenas rompe-huelgas o "crumiros", que en algunos casos llevó a actos violentos como ponerle polleras por la fuerza, con el propósito de humillarlos para que "tomaran conciencia"33. Pinto, Valdivia y Artaza, compartiendo en gran parte los postulados de González, observaron la construcción de la identidad pampina en las décadas que antecedieron a la Guerra del Pacífico (también conocida como Guerra del salitre), a partir de dos elementos: "el sentimiento nacional y el sentimiento de clase" que se amalgamaron para configurar la construcción de dicha identidad 34 .

Respecto a la situación mapuche, Saavedra apuntó que la población mapuche tuvo una doble identidad, indígena y campesina, que se sintetizó en una subcultura étnica de resistencia. Esta situación les permitió llevar a cabo alianzas con el movimiento obrero y campesino, sobre todo durante la reforma agraria, donde tuvieron activo protagonismo en la recuperación de tierras ("corridas de cercos)"35. Durante el Gobierno de la Unidad Popular, Coronado admite las particularidades de la cultura mapuche, contrastando la posición de Saavedra; asumiendo la integración a la vida sociedad sin asimilación, pero tampoco la autodeterminación que propiciaba Lipschutz ${ }^{36}$. Como se puede apreciar, la reforma agraria, sin duda, fue un proceso relevante de la participación política indígena. Existe una amplia producción historiográfica reciente sobre la reforma agraria en las zonas de Cautín y Arauco-Malleco ${ }^{37}$, que describe y explica el protagonismo de los mapuche en

\footnotetext{
32 Augusto Samaniego y Carlos Ruiz, Op. Cit, 2003.

33 Sergio González, "La presencia indígena en el enclave salitrero de Tarapacá: una reflexión en torno a la fiesta de la Tirana", Chungará 38 (1), 35-49, Arica, 2006.

34 Julio Pinto, Verónica Valdivia y Pablo Artaza, "Patria y clase en los albores de la identidad pampina (18601890)", Historia, Vol. 36, 275-332, Instituto de Historia Pontificia Universidad Católica de Chile, $2003,277$.

35 Alejandro Saavedra, Los Mapuche en la sociedad chilena actual, Santiago, LOM, 2002.

36 Luis Coronado Castillo, “El problema mapuche”, América Indígena, vol. XXXIII, N² 2, abril junio, pp. 495-524, Ciudad de México, 1973.

37 Jesús Ángel Redondo, “Las tomas de fundos en la provincia de Cautín (Chile), 1967-1973”, Cuadernos de historia (Santiago), (42), 2015; Raúl Molina Otarola, “Geografías mapuches: territorios, política y desafíos en tiempos de cambio", Revista geográfica del sur, 3(1): 15-36, 2012; Martín Correa y Eduardo Mella, Las razones del "illkun"/enojo. Memoria, despojo y criminalización en el territorio mapuche de Malleco, Santiago, LOM Ediciones y Observatorio de Derechos de los Pueblos Indígenas, 2010; Mathias Órdenes Delgado, “Conflicto mapuche-campesino en la Araucanía”, Izquierdas [En línea], 26 | enero 2016, Publicado el 01 enero 2016, consultado el 16 agosto 2019. URL: http://journals.openedition.org/izquierdas/637
} 
conjunto con las organizaciones políticas institucionalistas y las insurreccionalistas, de la izquierda. Para Mariman, miembro de la Comunidad de Historia Mapuche, la reforma agraria fue un "acto reparatorio de un patrimonio que siempre les había pertenecido como pueblo, por lo mismo la tierra se reivindicaba más que demandaba" 38 , aunque la UP hiciera "vista gorda" a los derechos de autodeterminación de los pueblos indígenas.

Otro hecho relevante que expone la relación del PC y los pueblos indígenas fue la matanza de campesinos y mapuche en Ranquil (1934) ${ }^{39}$. Según Klubock, a fines de junio de 1934, campesinos mestizos e indígenas mapuches en las fincas Ránquil y Guayalí invadieron grandes propiedades, atacaron a los propietarios y gerentes, $\mathrm{y}$, después de una semana, controlaron una gran franja de la provincia, amenazando los principales centros comerciales de la región. El PC tuvo una fuerte presencia mediante el apoyo a la fundación del Sindicato Agrícola Lonquimay, seis años antes, y en la entrega de folletos que pedían a los trabajadores rurales que organizaran soviets de campesinos, colonos y mapuche. Ambas organizaciones lideraron la revuelta, junto a los trabajadores de los lavaderos de oro ${ }^{40}$. $\mathrm{La}$ débil presencia del estado chileno en el sur en esta época, implicó la recurrencia a la violencia para ejercer autoridad ${ }^{41}$. Téllez et. al, establecen que, en los sucesos narrados, ocurrió una convergencia de discursos, por un lado, mapuche (expresado en el XI Congreso Araucano sobre "República Indígena") 42 y, por otro, comunista (referido a la proclamación de la "República Araucana" aparecida en los órganos de propaganda del PC instigada por el MCI) ${ }^{43}$. Según Ulianova, a partir de la revisión de documentos oficiales de la Komintern, expone que el accionar del PC en la zona, se confirma por medio del cumplimento de la "estrategia del tercer período" que predisponía la Internacional Comunista en esa época, aunque matiza su participación que fue amplificada en Moscú por el secretario político de la época, C. Contreras Labarca 44 .

En el caso de Magallanes, Harambour sostiene que el discurso clasista fue la base de la aglutinación de la clase trabajadora, aunque veladamente se mantenía una discriminación

\footnotetext{
38 Pablo Mariman Quemenado, “El pueblo mapuche y la Reforma Agraria: una reforma entre cuatro contrarreformas", Revista anales de la Universidad de Chile, Séptima serie. No 12/2017, 265.

39 La Masacre o Levantamiento de Ranquil (junio y julio de 1934), fue la dura represión en contra de un conjunto de obreros, campesinos y mapuche, en la provincia de Lonquimay, que protestaba por las condiciones de trabajo y la usurpación de tierras.

40 Thomas Miller Klubock, “Ranquil: Violence and Peasant Politics on Chile's Southern Frontier", Greg Grandin y Gilbert Joseph, A Century of Revolution: Insurgent and Counterinsurgent Violence during Latin America's Long Cold War, Durham, Duke University Press, 2010.

41 Thomas Miller Klubock, La Frontera Forests and Ecological Conflict in Chile's Frontier Territory, Durham, Duke University Press, 2014.

42 Rolf Foerster y Sonia Montecino, Organizaciones, líderes y contiendas mapuches (1900 - 1970), Santiago, CEM, 1988. 43 Eduardo Téllez, Cristián Arancibia, Juan Canales, Larisa de Ruit, Rodrigo Quinteros y Yuri Quintupirray, “El levantamiento del a Alto Bío- Bío y el Soviet y la República Araucana de 1934", Anales de la Universidad de Chile Sexta Serie, No13, agosto de 2001.

44 Olga Ulianova, "El levantamiento campesino de Lonquimay y la Internacional Comunista", Estudios Públicos número 89, Santiago, 2003.
} 
a los/as trabajadores/as provenientes de Chiloé, a pesar de ser un actor político relevante cuantitativa y cualitativamente ${ }^{45}$.

Como se puede apreciar, existe una profusa bibliografía que aborda la relación entre las agrupaciones de izquierda y los pueblos indígenas, desde diferentes puntos de vista. Sin embargo, se enuncia en estos trabajos, la existencia de dicha relación a partir de una dialéctica desplegada que vincula a ambos actores sociales, a partir de diferentes expresiones en distintos pueblos indígenas y contextos espacio-temporales.

\section{Técnicas metodológicas}

Las técnicas metodológicas empleadas fueron los análisis de contenido y crítico de discurso. La primera técnica hace referencia al análisis de la información cuantitativa (cifras de aparición de la temática indígena en los medios de comunicación del PC) de manera fragmentada, es decir la búsqueda de conceptos en los períodos analizados por separado ${ }^{46}$. La segunda técnica refiere al estudio de la información como una totalidad, a partir de una interpretación cualitativa que sugiere la posibilidad de identificar relaciones de dominación y sojuzgamiento ${ }^{4}$. A partir del uso de estas técnicas, se establecieron ciertas regularidades dentro de los discursos y conceptos transversales a los distintos períodos. Estas técnicas permitieron concebir el fenómeno por medio de las categorías conocidas como parte y todo, provenientes de la filosofía clásica alemana y reelaboradas por Marx. Dichas categorías refieren a la relación que se puede establecer entre un conjunto de elementos y la conexión que los agrupa, y que promueve el establecimiento de particularidades, no comprensibles en cuanto a la interpretación de los elementos ubicados aisladamente ${ }^{48}$.

La información consultada fue de carácter secundario, y obtenida de la revisión hemerográfica de los medios de comunicación del PC que trataron temáticas relativa a los indígenas. Otras fuentes de información que fueron consultadas, fueron los documentos teóricos, revistas, panfletos y escritos en general, elaborados institucionalmente por el PC, durante el periodo establecido para realizar el estudio. La búsqueda de información secundaria se realizó en la Biblioteca Nacional de Santiago. Merced al extenso período escogido para investigar, las fuentes de información fueron seleccionadas en base a un principio aleatorio. Se seleccionaron 6 meses por año, y una semana de cada mes escogido, en esta semana se revisó la producción prensa generada por el PC. Los periódicos analizados fueron El Despertar de los Trabajadores (1912-1918 y 1921-1926), Bandera Proletaria (1933),

45 Alberto Harambour, "Racialización desde afuera, Etnicización hacia adentro. Clase, región y etnicidad en el movimiento obrero de la Patagonia Austral, principios del siglo XX", Rafael Gaune y Martín Lara (eds.), Historias de racismo y discriminación en Chile, Santiago, Uqbar Editores, 2009.

46 Bernard Berelson, Content Analysis in Comunication Research, Glencoe, Free Press, 1952.

47 Teun A. van Dijk, “El análisis crítico del discurso”, Anthropos 186, (Barcelona), septiembre-octubre 1999, pp. 23-36.

48 “ ¿Cómo podemos conocer el todo antes de las partes, si esto supone conocer las partes antes del todo? La solución de esta paradoja tiene como base la unidad dialécticamente comprendida entre el análisis y la síntesis. El conocimiento del todo y de las partes es un proceso simultáneo: al discriminar las partes, las analizamos como elementos del todo dado, mientras que, gracias a la síntesis, el todo aparece como dialécticamente desintegrado y compuesto por las partes". Pavel Iudin y Mark Rosental, Diccionario de filosofía Marxista, Buenos Aires, Seneca, $1959,83-84$. 
Bandera Roja (1931-1934), Justicia (1924-1927 y 1931-1936), CTCH (1939) y El Siglo (1940-1948 y 1952-1973).

La recolección de dicha información permitió la elaboración de catastro general de información. Dicho catastro contiene las menciones de la problemática en periódicos ligados al PC, separadas en dos grandes grupos: menciones directa e indirecta. Ésta última refiere al tratamiento de la problemática indígena nacional de manera tangencial, orientada a la discusión y exposición de la situación de indígenas o grupos de otros países, la crítica al concepto de civilización burguesa, etc. La mención directa está relacionada con las informaciones acerca de la situación concreta de la población indígena existente en el país.

El catastro contiene la información para la construcción de series que permitieron analizar la frecuencia de la aparición de la temática indígena en periódicos comunistas. A partir de estas series de datos se desprendieron los resultados y conclusiones de cada período en particular. Mediante la utilización de la información recogida en la mención directa, se construyeron indicadores relativos a determinadas variables significativas a la problemática indígena (tabla 1). Esto permitió analizar tanto la cualidad como la cantidad del fenómeno en aras de comprender más cabalmente la transformación de la estructura del mismo a través del tiempo.

Tabla 1. Variables e Indicadores del discurso del PC respecto los pueblos indígenas

\begin{tabular}{|c|c|c|c|c|}
\hline Política & Judicial/Delictivo & Económica & Identidad étnica & Racial \\
$33,8 \%$ & $30,1 \%$ & $18,0 \%$ & $14,0 \%$ & $4,0 \%$ \\
\hline
\end{tabular}

Indicadores

\begin{tabular}{|c|c|c|c|c|}
\hline Política & Judicial/Delictivo & Económica & Identidad étnica & Racial \\
\hline $\begin{array}{c}\text { Defensa de } \\
\text { tierra/acción } \\
\text { directa } \\
35,9 \%\end{array}$ & $\begin{array}{c}\text { Defensa jurídica } \\
22,0 \%\end{array}$ & $\begin{array}{c}\text { Reforma Agraria } \\
18,4 \%\end{array}$ & $\begin{array}{c}\text { Representaciones } \\
\text { artísticas } \\
31,6 \%\end{array}$ & $\begin{array}{c}\text { Reivindicación } \\
\text { racial } \\
54,5 \%\end{array}$ \\
\hline $\begin{array}{c}\text { Participación } \\
\text { Organización } \\
\text { política/militar } \\
40,2 \%\end{array}$ & $\begin{array}{c}\text { Reclamo de tierras } \\
31,7 \%\end{array}$ & $\begin{array}{c}\text { Despojo/ } \\
\text { restitución de } \\
\text { tierras } \\
46,9 \%\end{array}$ & $\begin{array}{c}\text { Invenciones } \\
\text { culturales } \\
7,9 \%\end{array}$ & $\begin{array}{l}\text { Denuncia de } \\
\text { racismo } \\
45,5 \%\end{array}$ \\
\hline $\begin{array}{c}\text { República } \\
\text { Araucana } \\
4,3 \% \\
\end{array}$ & $\begin{array}{c}\text { Atropello/muerte } \\
\text { a indígenas } \\
39,0 \% \\
\end{array}$ & $\begin{array}{c}\text { Especialización } \\
\text { técnica } \\
2,0 \% \\
\end{array}$ & $\begin{array}{c}\text { Defensa de } \\
\text { Costumbres } \\
44,7 \% \\
\end{array}$ & \\
\hline $\begin{array}{l}\text { Solidaridad } \\
\text { política } \\
18,5 \%\end{array}$ & $\begin{array}{c}\text { Víctimas de la } \\
\text { justicia } \\
7,3 \%\end{array}$ & $\begin{array}{c}\text { Defensa de } \\
\text { producción/ } \\
\text { Comunidades } \\
32,7 \%\end{array}$ & $\begin{array}{c}\text { Reivindicación } \\
\text { de héroes } \\
\text { culturales } \\
15,8 \%\end{array}$ & \\
\hline
\end{tabular}




\section{Etapas de la historia del PC respecto a la participación política indígena}

Las etapas de la historia del PC con respecto a la participación política indígena fueron organizadas en 5 períodos: A. Origen y formación del PC y su despliegue nacional (1912-1933), B. Ranquil, discrepancia en torno a la participación comunista y Mapuche (1932-1934), C. Línea comunista en torno al proyecto de revolución democrática-burguesa, El Frente Popular y su quiebre (1935-1947), D. Ley de defensa permanente de la democracia, la aglutinación de nuevas fuerzas y la mantención de la política de alianzas amplias: Conformación del Frente del Pueblo, la CUT, la ANI, el FRAP y la Federación nacional campesina e indígena (1948-1969) y E. Participación del PC en el gobierno de la UP (19691973).

A partir del diseño de estas etapas, se llevó a cabo el análisis de la información relativa a la problemática indígena aparecida en medios de comunicación del PC (ver gráfico 1), y se puede sustentar, a modo de resultado general, que la proyección discursiva del PC acerca de esta problemática, fueron esencialmente, de carácter político y judicial/delictiva. Esto se desprende de la exposición de los porcentajes de las variables e indicadores de la Tabla 1. La frecuencia de aparición de la problemática indígena, estuvo sujeta al contexto político, cultural, ideológico y económico del país, en el cual el PC maniobró y diseñó políticas hacia la población y movimientos de corte étnico.

En contraposición a la idea difundida extensamente en cuanto a que el PC interpretó la problemática indígena como una mera situación económica, existe dentro de la revisión desplegada, la frecuencia de aparición ligada fundamentalmente a temáticas políticas y judiciales/delictivas, seguidas de las temáticas económicas, identitarias y raciales.

La trayectoria del discurso del PC con respecto a la participación política indígena, se experimentó como un proceso discontinuo, irregular y coyuntural. Sin embargo, permaneció en el discurso, la idea de superación de las condiciones sociales inicuas, que hicieron posible el sojuzgamiento de la población mapuche. En este contexto, se puede plantear la disposición pretérita de un proceso formal, pensado estructuralmente y basado en reflexiones a largo plazo, en función de la superación de la subordinación de esta población.

El momento más alto de la frecuencia de la aparición de la problemática indígena se registró en la década de los cuarenta, período posterior a la matanza de Ranquil, y que estableció la reivindicación legal de las demandas de los indígenas. Dicha variable, judicial/delictiva, retomó fuerza en la década de los sesenta cuando los indígenas acometieron acciones directas de recuperación de tierras. El indicador detectado con mayor frecuencia, está asociado a la exposición de situaciones en las cuales, el indígena aparece como un sujeto social sometido a constantes atropellos. La curva de la variable política, registró una presencia constante dentro del período analizado. Los indicadores con mayor aparición fueron los ligados a la defensa de la tierra, acciones directas y la estimulación de la participación orgánica de los indígenas. En algunos casos, esta última, puede estar caracterizada por la difusión de las actividades de las estructuras políticas indígenas. Por otro lado, se sugería el ingreso de los grupos indígenas al PC. 
La variable económica está compuesta por indicadores relativos a la promoción y defensa de la reforma agraria, el despojo y restitución de tierras, y, por último, la defensa de las comunidades y lo producido en ellas. Presentando un bajo perfil, se encuentra la especialización técnica de los indígenas. Esto resulta entendible porque se subordinó dicho ítem a la reforma agraria. Dentro de este contexto se puede apreciar que no son necesariamente factores económicos, los claves para comprender la problemática indígena proyectada por el PC de Chile.

Gráfico 1 Frecuencias de aparición y porcentajes del discurso del PC respecto los pueblos indígenas (1912-1973)

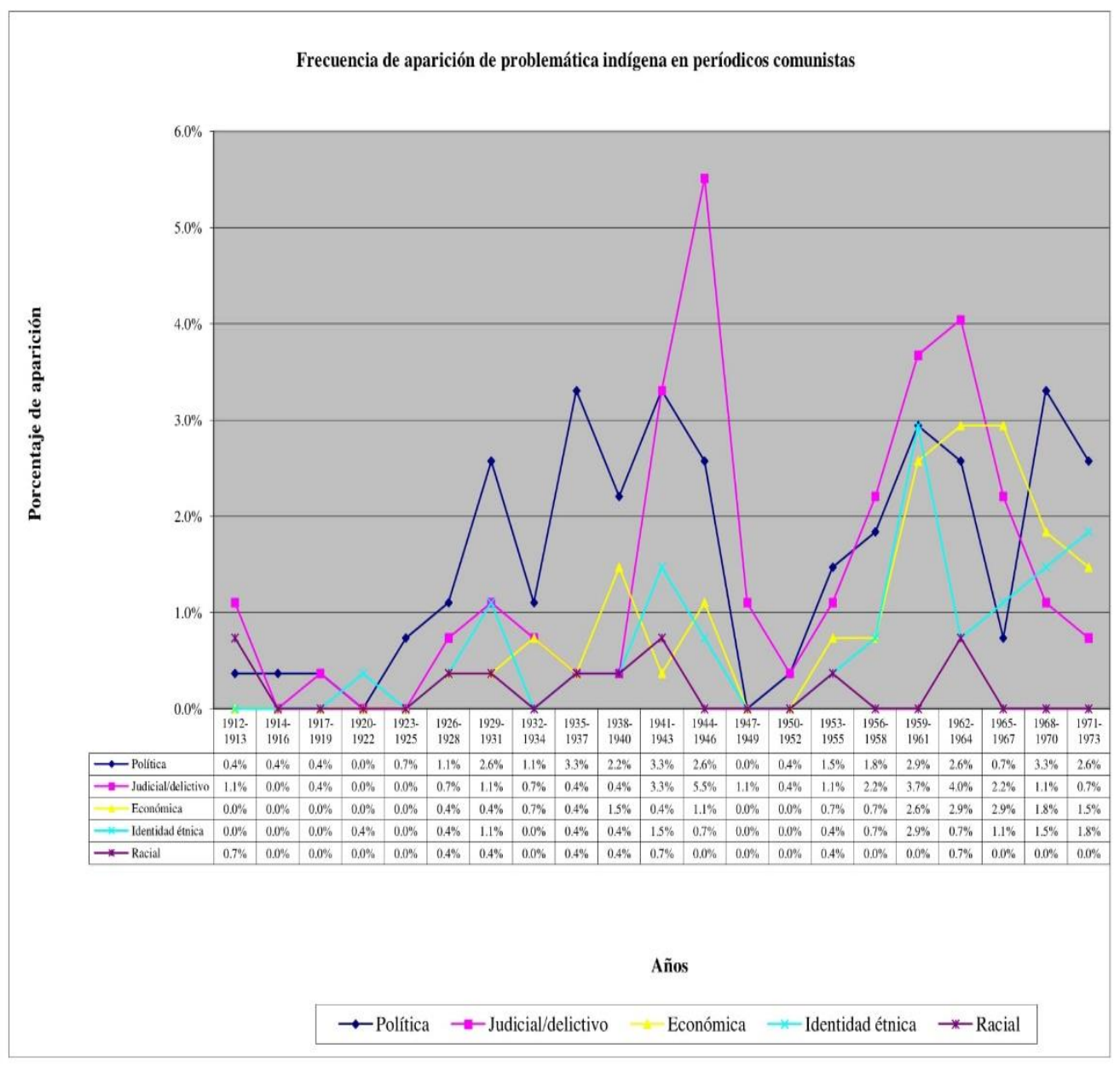


La pendiente que ilustra el movimiento de la variable identitaria étnica, demuestra que el interés por parte del PC acerca de estos hechos, tuvo una aparición irregular. Apareció con la proclamación de la República Araucana y se presentó irregularmente con el abandono de esta propuesta autonómica, desapareciendo a mediados de la década de los cuarenta y reapareciendo a mediados de la década de los cincuenta. Retomando fuerza a principios de los sesenta, la variable tomó cuerpo en la defensa de las costumbres de los indígenas, significándolas como contemporáneas y pertenecientes a la identidad chilena. Por otro lado, en este período se reivindicaron héroes culturales, representados como iconos de la izquierda en cuanto a su resistencia a la dominación española.

La variable más insignificante fue la racial. Se puede trazar que la interpretación comunista acerca de la problemática indígena no fue a partir de criterios raciales. Los indicadores relacionados con esta temática tienen que ver con la reivindicación racial, en el sentido de demarcar que los grupos indígenas no pertenecían a "razas inferiores". Por otro lado, se denunció al racismo como una explicación superficial a la problemática indígena y justificación de la opresión material.

La trayectoria de los discursos y las prácticas del PC respecto de la significación política de los indígenas (Tabla 2), estuvo basada en dos lógicas, las cuales son contradictorias, pero simultáneamente, complementarias. La primera refiere a la ambición que tuvo la izquierda, y en este caso del PC, por contener dentro de sí, a todas las reivindicaciones de quienes consideraba explotados/as. Es decir, planteó generar discursos y prácticas que aglutinasen a la mayor cantidad posible de personas que se encontraban bajo la dominación de la burguesía y los terratenientes. Es decir, concibió la liberación del proletariado del yugo de la burguesía, coincidentemente con la de otros explotados, en este caso campesinos e indígenas.

Lo anterior ocurrió en todos los períodos analizados, puesto que en forma transversal estuvo presente el argumento de que la cuestión social, en general, y problemática indígena, en particular, fue producto de la explotación económica acontecida desde el principio de la invasión española hasta la implementación de los gobiernos encargados de proteger los intereses de la burguesía y los terratenientes. Esto se puede comprender, pues la plataforma política comunista ambicionó plantear holísticamente los problemas sociales. En estricto rigor, el planteamiento marxista utilizado, privilegió el análisis de la realidad como una otalidad formada por particularidades contradictorias. Aspiró comprender lo concreto como "síntesis de múltiples determinaciones, por lo tanto, unidad de lo diverso".

La segunda lógica tiene relación con el hecho de que reconoció significativamente la participación de los diferentes grupos, por medio de la exaltación de sus demandas específicas, en los medios de comunicación del partido. Esto ocurrió porque se estableció 


\section{Tabla 2}

Trayectoria del discurso y la práctica del Partido Comunista de Chile con respecto a la participación política indígena

\begin{tabular}{|c|c|c|c|c|}
\hline $\begin{array}{l}\text { Contextos históricos } \\
\text { Etapas de los discursos } \\
\text { y las prácticas }\end{array}$ & $\begin{array}{l}\text { Contexto } \\
\text { internacional } \\
\text { comunista }\end{array}$ & $\begin{array}{l}\text { Contexto } \\
\text { nacional }\end{array}$ & $\begin{array}{c}\text { Política del } \\
\text { PC en general }\end{array}$ & $\begin{array}{l}\text { Discurso y acción } \\
\text { del PC respecto } \\
\text { los indígenas }\end{array}$ \\
\hline $\begin{array}{c}\text { A. Origen y formación del } \\
\text { Partido Comunista de Chile } \\
\text { (PC) y su despliegue nacional } \\
\text { (1912-1933) }\end{array}$ & $\begin{array}{c}\text { - Estallido de la } \\
\text { 1ra Guerra } \\
\text { mundial } \\
\text { - Revolución } \\
\text { rusa } \\
\text { - Retiro de la } \\
\text { Guerra de } \\
\text { Rusia } \\
\text { - Fundación de } \\
\text { la Komintern y } \\
\text { el Bureau } \\
\text { Sudamericano }\end{array}$ & $\begin{array}{l}\text { Consolidaci } \\
\text { ón del } \\
\text { movimiento } \\
\text { obrero } \\
\text { - Represión } \\
\text { al } \\
\text { movimiento } \\
\text { obrero } \\
\text { - Dictadura } \\
\text { ibañista }\end{array}$ & $\begin{array}{c}\text { - Origen del } \\
\text { POS y } \\
\text { transformació } \\
\text { n en PC } \\
- \\
\text { Bolchevizació } \\
\text { n de la } \\
\text { política y de } \\
\text { las } \\
\text { estructuras } \\
\text { - Política del } \\
\text { FUP }\end{array}$ & $\begin{array}{c}\text { - Acercamiento a } \\
\text { la realidad } \\
\text { indígena por } \\
\text { medio de lo } \\
\text { campesino } \\
\text { - Influencia del } \\
\text { PC y la FOCH en } \\
\text { la conformación } \\
\text { de las primeras } \\
\text { organizaciones } \\
\text { agrarias con } \\
\text { participación } \\
\text { indígena }\end{array}$ \\
\hline $\begin{array}{l}\text { B. Ranquil, discrepancia en } \\
\text { torno a la participación } \\
\text { comunista y Mapuche } \\
(1932-1934)\end{array}$ & & & & \\
\hline
\end{tabular}




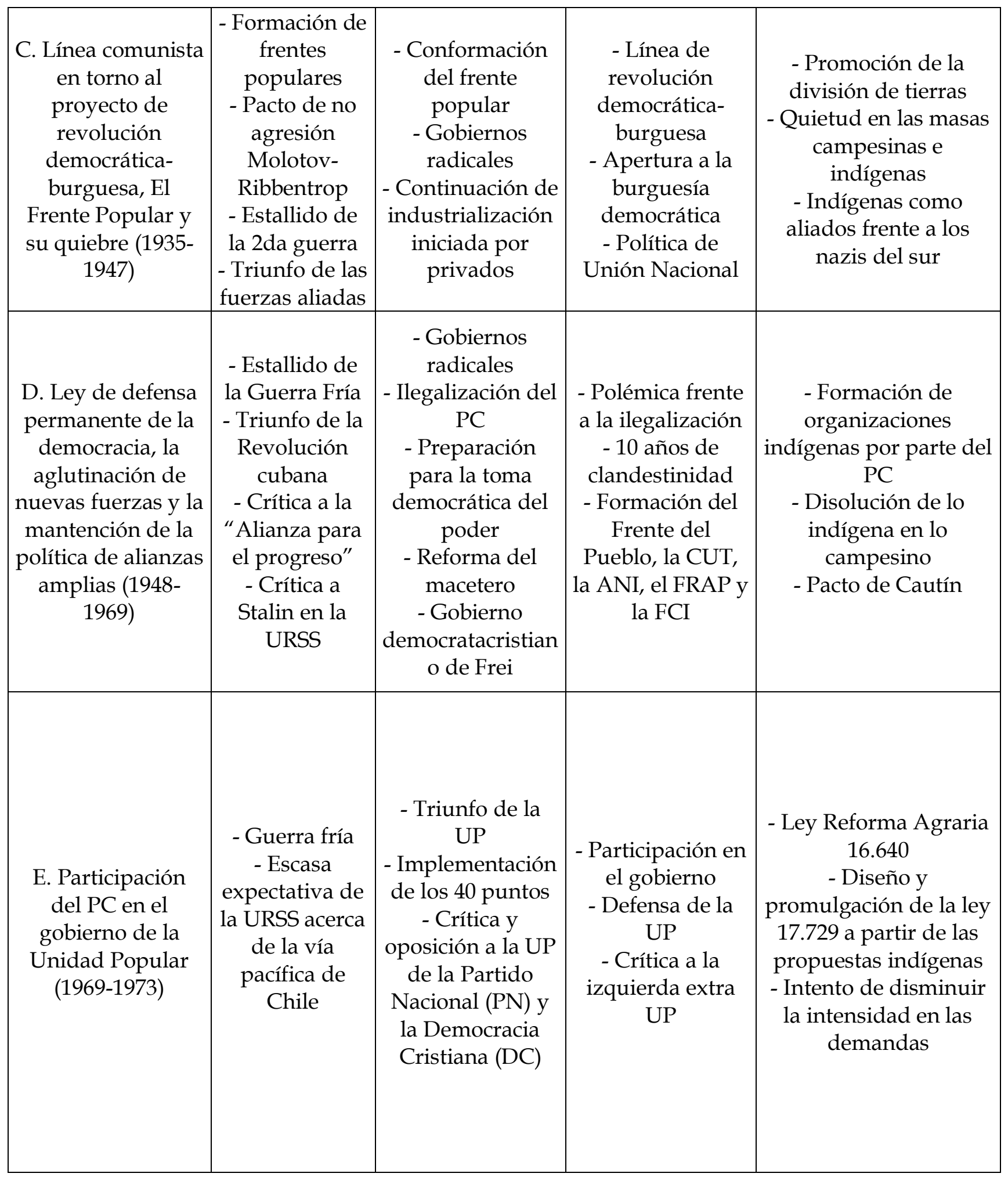


un encuentro de intereses entre los indígenas y el PC, en determinados contextos históricos, como por ejemplo en el caso de Ranquil.

Teniendo presente estas discusiones, es posible presentar el pensamiento comunista como amplio, en la medida que dentro de sí mismo se encontraron diversas posiciones que se contrapusieron, desde posiciones que plantearon i) la autonomía de los grupos étnicos pasando por posiciones que asumieron ii) la necesidad de proteger sus costumbres dentro del Estado, hasta posturas que establecieron la posibilidad de iii) asimilar completamente a los indígenas al extremo de convertirlos en chilenos, negando su especificidad étnica.

En estas tres situaciones podría sintetizarse las diferentes etapas del discurso y la práctica del PC. En el trabajo realizado fue posible encontrar estas tres realidades y, así pues, viable argumentar cierta la existencia de una política pretérita múltiple desde el PC hacia los indígenas.

La primera posición es posible encontrarla en el período que abarca la fundación del PC hasta la matanza de Ranquil ${ }^{49}$. Este planteamiento contuvo la posibilidad de conexión entre la identidad étnica y la clase social, en la medida que su análisis, no abandonó el contenido étnico de las poblaciones indígenas, pero tampoco excluyó la posibilidad de comprenderlas dentro de conflictos de clases. En cuanto a lo sucedido en Ranquil, la reflexión y acción del PC en torno a los indígenas en este período estuvo atravesada por la caracterización de las sociedades indígenas como "minorías nacionales". Esta clasificación fue fomentada por el Bureau Sudamericano de la 3ra internacional, el cual planteaba a las diferentes secciones, la necesidad de abordar la problemática indígena a partir de la solución aplicada en la URSS, mediante la implementación de repúblicas autónomas y federadas ${ }^{50}$. La segunda posición se ubica desde el retorno del PC a la legalidad (1958) hasta el golpe militar de 1973. En esta época, este partido no buscó la disolución de la comunidad indígena, así como tampoco expuso la consigna de ofrecer a los grupos indígenas la organización política que estimasen conveniente. Las acciones del PC se orientaron a la colaboración en provecho de organizar agrupaciones indígenas, con el objetivo de sumarlas al proyecto nacional de transformación, asegurándoles un lugar dentro de la estrategia para alcanzar el poder y la posibilidad de preservar sus características culturales, lingüísticas, organizacionales y productivas ${ }^{51}$.

\footnotetext{
49 El pensamiento crítico al indigenismo de Lipschutz, puede ser situado en esta categoría ya que podría ser visto como antecedente del indianismo porque este académico plantea al indígena como actor social constructor de su realidad a través del proceso de lucha social.

50 Julio Humbert, "Proyecto de tesis sobre el problema de las razas" en La correspondencia sudamericana, 2da época número 15, Bs. As., agosto de 1929, pp. 25-30. Republicado en "Socialismo y Participación", CEDEP, Lima, Perú, 1980, página 33; Olga Uliánova, O. Cit., 2003; Sebastián Leiva, "El partido comunista de Chile y el levantamiento de Ranquil", Cyber Humanitatis No28, primavera 2003, Disponible en https://web.uchile.cl/vignette/cyberhumanitatis/CDA/texto_simple2/0,1255,SCID\%253D6781\%2526ISID\%2 53D374,00.html

51 Rolando Álvarez, "Viva la revolución y la patria", Revista de Historia social y de las mentalidades "La construcción histórica del socialismo en Chile", Año VII, Volumen 2, Santiago, Chile, 2003, página 42.
} 
La tercera posición está ligada al alejamiento de la política del Frente Único Proletario (FUP) y a las alianzas producidas para la conformación del Frente Popular. En este período el PC, en función de sostener la relación con sus aliados, mantuvo las demandas campesinas e indígenas en sosiego, puesto que estaba siendo constantemente interpelado por su participación en los gobiernos radicales. Por ello, durante los debates parlamentarios apoyó las iniciativas del ejecutivo guiadas a la disolución de la comunidad indígena. Estos hechos permiten establecer que esta etapa estuvo bajo las coordenadas del asimilacionismo, ya que se estimaba que el indígena carecía de una gran diferencia respecto a los campesinos pobres y por ello, debía integrarse en plenitud a la nación chilena, mediante el mestizaje. Las principales conclusiones de este estudio pueden sintetizarse en: a) la existencia de discursos elaborados desde el PC hacia los indígenas, b) la transformación de los discursos del PC a través del tiempo y c) elaboración teórica adaptada y resignificada para explicar la problemática indígena y que, de una u otra manera, posibilitaron la comprensión de los hechos relativos a dicha problemática.

Estos tres hechos demuestran la compleja relación que se estableció entre el PC y los grupos indígenas puesto que dan cuenta de la existencia de discursos maleables, cambiantes e influenciables por los acontecimientos que ocurrieron tanto interna como externamente. Es asequible, dentro de este contexto, plantear que los discursos elaborados por el PC, fueron producto del tiempo histórico en el cual se desplegaba la acción política comunista. Ahora se procederá a detallar las tres conclusiones descritas anteriormente.

\section{Conclusiones}

La primera conclusión que puede establecer este trabajo, es la existencia efectiva de diferentes discursos pretéritos del PC de Chile, para comprender la presencia de los pueblos indígenas en el país, y, junto a ello, una serie de prácticas más o menos concordantes con aquellos discursos. La hipótesis central de esta investigación fue la construcción diversos discursos integradores, realizada por el Partido Comunista de Chile, desde su origen hasta el golpe militar de 1973, en virtud de incluir a los pueblos indígenas existentes en el país, en especial, al mapuche, a las luchas políticas promovidas por el partido. Dicha inclusión fue tomando cuerpo a lo largo del devenir de la historia del partido, en la medida que los discursos partidarios concibieron a los grupos étnicos como asimilables a un sector más amplio de la población (obreros, campesinos, pobladores), caracterizado por encontrarse bajo "el sometimiento de las clases dominantes". El intento del PC durante gran parte de las etapas analizadas, fue la conformación de conglomerados políticos amplios con la participación de diferentes grupos sociales, partidos y movimientos.

Los indígenas, por su parte, elaboraron diversas estrategias para encarar los acontecimientos políticos, económicos y sociales en los cuales interactuaban. Esas estrategias produjeron alianzas, conformación de parlamentos, penetración de individuos 
en organizaciones de corte occidental, configuración de sindicatos y organizaciones indígenas de carácter clasista52.

Hay que enfatizar el carácter de los movimientos indígenas como respuesta a sus condiciones de existencia, en el marco de una sociedad que estuvo cruzada por tensiones sociales producto de proyectos de transformación. Por ende, no se trata, en este caso, de una manipulación antojadiza respecto de los movimientos indígenas para imponer objetivos políticos en la sociedad. Se trata, por el contrario, de una relación dialógica entre dos sectores: por un lado, el PC que intentó dar cuenta de las demandas de la población desposeída por medio de la organización y colaboración; y, por el otro lado, la población indígena sometida a sistemáticos abusos del Estado y privados, que buscaba la manera por la cual superar dichas iniquidades.

De esta manera, el PC proyectó la situación del indígena como una problemática que tuvo su origen en "la opresión de las distintas clases dominantes que se han turnado en el poder". Sin embargo, dicha conceptualización de la problemática indígena operó como base de variados discursos no necesariamente homogéneos. Esta segunda conclusión plantea que aquellos discursos estuvieron concebidos por los militantes, por medio del empleo de conceptos claves ("minoría nacional", "República Autónoma Araucana", "campesino pobre", "proletario mapuche", etc.), que conformaron la estructura de dichos discursos acerca de la problemática indígena, y que orientaron determinadas acciones en contextos históricos delimitados. Los discursos elaborados desde el comunismo chileno respecto a los indígenas no solamente fueron diferentes a través de las distintas etapas históricas analizadas; en algunos casos, fueron contradictorios entre sí. Por tanto, es posible sostener la presencia de un discurso múltiple y variante, en tanto que acaecieron propuestas diferentes que abarcaron desde la posibilidad de la autonomía indígena hasta el apoyo a la propuesta de asimilación completa de la población indígena al "Estado-nación chileno", implementadas por el indigenismo de los gobiernos radicales.

En cuanto al análisis ideológico de lo que se menciona, fue factible encontrar en el discurso y práctica de los comunistas hacia los indígenas, la disposición de conceptos claves dentro de cada período de esta trayectoria. Por ejemplo, en el período que abarcó el origen del PC hasta los acontecimientos de Ranquil, principalmente, el concepto utilizado para referirse a los indígenas, fue de "minoría nacional oprimida". Por "minoría nacional" se entendió la coexistencia de grupos étnicos oprimidos y sometidos por la nacionalidad dominante, los cuales conformaban nacionalidades herederas de cualidades políticas, económicas, orgánicas y culturales, que les daban la facultad de organizar sus propios estados, en este caso, la posibilidad de conformar la "República Autónoma Araucana", independiente a la existencia del Estado de Chile. Los acontecimientos de Ranquil, por ende, son relevantes en la medida que fue el primer intento histórico por parte de los/as comunistas chilenos en cuanto a proponer la conformación de una "Republica dentro de otra República".

52 Rolf Foerster y Sonia Montecino, Op. Cit., 1988. 
Dentro de este marco, se defendió la propiedad comunal indígena en el parlamento, planteándose que si bien, los indígenas no representaban el sujeto revolucionario clásico del marxismo, ellos también se encontraban en una situación desmedrada, así como también campesinos, pobladores y trabajadores. Sin embargo, su particularidad radicaba en el hecho que representaban nacionalidades diferentes, las cuales pudieron haber conformado organizaciones político-organizativas autónomas.

Empero, esta conceptualización del PC no fue la hegemónica durante el periodo de estudio. Se puede registrar un cambio en la mirada del PC hacia el indígena, conforme al cambio de política asociada a las diferentes etapas por las cuales el partido recorrió.

Una vez aplacada la revuelta de Ranquil y la asimilación por parte del PC de la política de "Revolución democrática-burguesa", la cual supone el abandono de la política FUP y la conceptualización de la etapa histórica como una etapa posterior a la caracterizada como de “Tercer período". En este período, el PC no renunció al concepto de "minoría nacional", sin embargo, lo redefinió ligándolo a "campesino pobre", el cual proponía un sujeto indígena que debía integrarse a la nación chilena. Este nuevo concepto surgió en el escenario prebélico de la 2da guerra mundial, en el cual, los centros de poder comunistas internacionales sugerían a sus secciones, el aplacamiento de movimientos políticos de corte nacionalsocialistas, mediante la organización de "Frentes Populares" que hicieran frente a la amenaza fascista que se cernía sobre el mundo. Esta nueva definición involucró la interpretación de lo "indígena" como un fenómeno ligado exclusivamente a los espacios rurales (pequeña producción orientada al autoconsumo y residencia fundamentalmente en el campo), dejando de lado sus especificidades culturales.

Dicha definición fue fundamental dentro del período que se extendió desde la conformación del "Frente Popular" hasta mediados de los años sesenta. En dicho intervalo de tiempo, ocurrió la introducción de la temática indígena subsumida y homologada a los intereses del campesinado. No obstante, este período estuvo marcado por el rompimiento del "Frente Popular" y la ilegalización del PC en 1948, lo cual significó el cambio de la política asumida de división de las comunidades, hacia la promoción organizativa de los sectores indígenas con el objetivo de llevar a cabo una reforma agraria que les devolviera los territorios usurpados. Con la participación efectiva de un número importante de indígenas en el pacto de Cautín ${ }^{53}$, se puede plantear un cambio decisivo dentro de la izquierda chilena con respecto a la mirada sobre el indígena ${ }^{54}$.

\footnotetext{
53 Parlamento llevado a cabo el 6 de abril de 1964 (cerro Nielol), entre el candidato Salvador Allende y dirigentes mapuche de izquierda.

54 "El respeto a la cultura tradicional mapuche, había sido comprometido por Allende en 1964, en el Título II del Pacto de Cautín, que expresa: “Considerando que el pueblo araucano (sic) desea mantener y desarrollar todos aquellos aspectos positivos de su cultura tradicional y que enriquecen el acervo de la cultura nacional chilena como su lenguaje, sus leyendas, sus ideas religiosas, y sus artesanías..." Por eso no se puede sostener que el gobierno de la UP y la izquierda en general, no supieron respetar las particularidades de la cultura mapuche y que la sumieron simplemente dentro de la cuestión campesina”. Carlos Ruíz Rodríguez, "El pueblo mapuche y el gobierno de Salvador Allende y la Unidad Popular", Universidad de Santiago de Chile, Proyecto DICYT 030051 SM La cuestión mapuche: Chile, 1964-1973. Discursos y prácticas desde el Estado y la sociedad civil hacia las minorías étnicas, 2005.
} 
Dicho proceso de transformación de la conceptualización del indígena, derivaría ulteriormente en la promulgación de la ley 17.729, la cual sentaría un antecedente, primero, dentro de la trasformación de la mirada del PC hacia los grupos étnicos, en cuanto a la participación activa indígena en la redacción del proyecto de ley y, segundo, dentro de la superación de la visión del indígena como un simple productor a baja escala situado en zonas rurales 55 .

La tercera conclusión de este trabajo, puede resumirse en el intento del PC por interpretar los diferentes escenarios y actores que emergieron. Esto se produjo en la medida que la interpretación de esta temática, en muchos casos, estuvo influenciada por las recomendaciones externas provenientes desde los centros comunistas internacionales, $\mathrm{y}$, sobre todo, desde Moscú y Montevideo, pero siempre a través de una mirada concordante con la situación nacional. Durante el camino, podría plantearse simplemente, que los militantes del PC de Chile, fueron descubriendo nuevos sujetos sociales, a los cuales debieron incluir dentro de los procesos políticos, lo cual, a su vez, se tradujo en nuevos desafíos y nuevas preguntas, que tuvieron que enfrentar y responder. Es posible destacar el carácter creativo de la política que llegó a desarrollar el PC. Sin duda, la creación del Partido Obrero Socialista (POS), el pensamiento de Recabarren, así como la contribución a la creación de diferentes movimientos políticos, entre los que destacan, especialmente, la Unidad Popular (UP), representan hechos inéditos dentro de la historia mundial del pensamiento marxista, en la medida que fueron capaces de desarrollar una plataforma política, que se diferenciaba de las "recomendaciones" externas y que proponía soluciones políticas conformes a la realidad del país.

Otro hecho relevante, fue la limitada aparición de otros pueblos indígenas. Generalmente, se presentó a los grupos indígenas como homogéneos, indiferenciados y poseedores de similares inquietudes. Es por ello, que son escasas las menciones a la existencia de otros pueblos como aymarás, atacameños, selk'nam, entre otros. Tampoco hubo un discurso de diferenciación que planteara la existencia de subgrupos (pewenches, huilliches, lafkenches, etc.) dentro de lo denominado "mapuche". Dentro de este contexto de diferenciación de los distintos pueblos indígenas existentes en el país, el PC tuvo herramientas limitadas para identificar las especificidades de estas culturas. Es decir, no tuvo, para estos efectos, elementos suficientes para describir y comprender a este tipo de sociedades en cuanto a sus diferencias, situando a la población mapuche, debido a su número, como la más importante. Empero, existió la voluntad política en ciertos momentos

\footnotetext{
55 “Lo que las organizaciones mapuches hacían resaltar era el hecho que por primera vez en la historia republicana a los mapuches se les dio la oportunidad de participar en la elaboración de su Ley Indígena. La Ley fue promulgada el 15 de septiembre de 1972 y a pesar de los cambios que sufrió en el Parlamento chileno, los mapuches la veían como una de las leyes más avanzada en materia indígena. Entre los artículos más importantes consideraba la restitución de tierras de acuerdo a los planos originales de los Títulos de Merced y las tierras mapuches se declaraban inajenables. Se creó el IDI (Instituto de Desarrollo Indígena) cuya función era aplicar la Ley Indígena con el propósito de promover el desarrollo económico, social y cultural del pueblo Mapuche". Pedro Cayuqueo, “La Ley Indígena de Allende era vista como una de las más avanzadas, Entrevista a Reynaldo Mariqueo". Disponible en http:/ / piensachile.com/2014/10/la-ley-indigena-de-allende-era-vista-como-una-delas-mas-avanzadas/
} 
específicos, en los cuales se hizo el esfuerzo por reconocer las particularidades específicas de dichos pueblos. Es por ello, que Lipschutz puede ser descrito como un pionero en este tipo de reflexiones, puesto que amalgamó el marxismo con la situación de los pueblos indígenas entendidos como agrupaciones con características culturales específicas.

La existencia de conceptos utilizados por el PC, para enfrentar la problemática indígena fue variada a través del tiempo y describe la maleabilidad para enfrentar el tema, lo que determinó una praxis en constante elaboración dentro de la política comunista acerca de la cuestión étnica.

Los desafíos para estudios futuros están ligados a la percepción que tuvieron los indígenas respecto a las políticas desarrolladas por el PC. Esto podría contribuir al contraste con los hechos que se describen dentro de este trabajo, para así alcanzar una visión más integral de la relación entre el PC y los indígenas.

Para concluir, es necesario establecer los aspectos no abordados en el presente estudio. Estos aspectos tienen que ver con la visión de los otros grupos, movimientos y partidos de izquierda sobre los grupos étnicos. En el futuro, sería satisfactorio realizar un estudio con las posturas del sector izquierdista en general, con el objetivo de arribar a una mirada más amplia sobre la relación entre la izquierda chilena y los pueblos indígenas.

\section{9_Bibliografía}

- Álvarez, Rolando, "Viva la revolución y la patria", Revista de Historia social y de las mentalidades "La construcción histórica del socialismo en Chile", Año VII, Volumen 2, Santiago, Chile, 2003.

- Albizú Labbé, Francisco, “El indigenismo de la Unidad Popular (Chile 1970-1973). Estado y Nación entre reformismo y realidad", Amérique Latine Histoire et Mémoire. Les Cahiers ALHIM [En línea], 28 | 2014, Publicado el 05 diciembre 2014- Disponible en: http://journals.openedition.org/alhim/5116.

- Althusser, Louis, La revolución teórica de Marx, Ciudad de México, Síglo XXI Editores, 1967.

- Barría, Jorge, El movimiento obrero en Chile, Santiago, Ediciones de la Universidad Técnica del Estado, 1971.

- Becker, Marc, “Mariátegui y el problema de las razas en América Latina”, Revista Andina 35, 2002.

- Bengoa, José, “La cuestión indígena y la situación de las minorías étnicas”, Proposiciones 18, Santiago, Sur, enero 1990.

- Berdichewsky, Bernardo, “La Visión Crítica de Lipschutz de la Antropología Moderna”, IV Congreso Chileno de Antropología, Santiago de Chile, Colegio de Antropólogos de Chile A. G., 2001.

- Berelson, Bernard, Content Analysis in Comunication Research, Glencoe, Free Press, 1952.

- Boccara, Guillaume, “Antropología diacrónica. Dinámicas culturales, procesos históricos y poder político”. En: Boccara, G. y Galindo, S. (editores). Lógica mestiza en América. Temuco, Instituto de Estudios Indígenas/Universidad de La Frontera, 1999. 
- Caniuqueo, Sergio, "Siglo XX en el Gulumapu: de la fragmentación del Wallmapu a la Unidad Nacional Mapuche. 1880 a 1978”, Pablo Marimán, Sergio Caniuqueo, José Millalén y Rodrigo Levil, j... Escucha, winka ...! Cuatro ensayos de Historia Nacional Mapuche y un epílogo sobre el futuro, Santiago, LOM Ediciones, 2006.

- Cayuqueo, Pedro, "La Ley Indígena de Allende era vista como una de las más avanzadas, Entrevista a Reynaldo Mariqueo". Disponible en http://piensachile.com/2014/10/la-leyindigena-de-allende-era-vista-como-una-de-las-mas-avanzadas /

- Coronado Castillo, Luis, “El problema mapuche”, América Indígena, vol. XXXIII, No 2, abril junio, pp. 495-524, Ciudad de México, 1973.

- Correa, Martín y Mella, Eduardo, Las razones del "illkun"/enojo. Memoria, despojo y criminalización en el territorio mapuche de Malleco, Santiago, LOM Ediciones y Observatorio de Derechos de los Pueblos Indígenas, 2010.

- Díaz-Polanco, Héctor, "Etnia, clase y cuestión nacional”, Cuadernos Políticos, número 30, Ciudad de México, editorial Era, octubre-diciembre de 1981, pp. 53-65.

- Fanon, Frantz, Los condenados de la tierra, Ciudad de México, 1983.

- Foerster, Rolf y Montecino, Sonia, Organizaciones, líderes y contiendas mapuches (1900 - 1970), Santiago, CEM, 1988.

- Godelier, Maurice, "Modo de producción asiático y los esquemas marxistas de evolución de las sociedades", Godelier, M., Marx, K. y Engels, F., Sobre el modo de producción asiático, Barcelona, Martínez Roca, 1972

- Gozzi, Gustavo, "Praxis", Norberto Bobbio, Nicola Matteucci y Gianfranco Pasquino (eds.), Diccionario de política L-Z, Ciudad de México, SXXI Editores.

- González, Sergio, “La presencia indígena en el enclave salitrero de Tarapacá: una reflexión en torno a la fiesta de la Tirana", Chungará 38 (1), 35-49, Arica, 2006.

- Harambour, Alberto, "Racialización desde afuera, Etnicización hacia adentro. Clase, región y etnicidad en el movimiento obrero de la Patagonia Austral, principios del siglo XX", Rafael Gaune y Martín Lara (eds.), Historias de racismo y discriminación en Chile, Santiago, Uqbar Editores, 2009.

- Humbert, Julio, "Proyecto de tesis sobre el problema de las razas" aparecido en "La correspondencia sudamericana", 2da época número 15, Bs. As., agosto de 1929, pp. 25-30. Republicado en "Socialismo y Participación", CEDEP, Lima, Perú, 1980.

- Iudin, Pavel \& Rosental, Mark, Diccionario de filosofía y sociología marxista, Buenos Aires, Seneca, 1959.

- Klubock, Thomas Miller, “Ranquil: Violence and Peasant Politics on Chile's Southern Frontier", Greg Grandin y Gilbert Joseph, A Century of Revolution: Insurgent and Counterinsurgent Violence during Latin America's Long Cold War, Durham, Duke University Press, 2010.

- Klubock, Thomas Miller, La Frontera Forests and Ecological Conflict in Chile's Frontier Territory, Durham, Duke University Press, 2014.

- Leiva, Sebastián, "El partido comunista de Chile y el levantamiento de Ranquil", Cyber Humanitatis No28, Primavera 2003, Disponible en 
- https://web.uchile.cl/vignette/cyberhumanitatis/CDA/texto_simple2/0,1255,SCID\%253 D6781\% 2526ISID\%253D374,00.html

- Lenin, Vladimir Ilich, "Tres fuentes y las partes integrantes del marxismo", marzo de 1913, Vladimir Ilich Lenin, Obras, Tomo V (1913-1916), Moscú, Edición Progreso, 1973.

- Lenin, Vladimir Ilich, "El derecho de las naciones a la autodeterminación", Vladimir Ilich Lenin, Obras completas, Tomo XXI, Madrid, Akal, 1977.

- $\quad$ Ley Indígena 17.729, Santiago, IDI, 1972.

- Lipschutz, Alejandro, La comunidad indígena en América y en Chile, Santiago de Chile, Editorial Universitaria, 1956.

- Lipschutz, Alejandro, "El régimen social de la URSS y su importancia para Hispanoamérica", Aurora, Segunda Época, N¹, Santiago, 1964.

- Lipschutz, Alejandro, El problema racial en la conquista de América y el mestizaje, Santiago, Editorial Andrés Bello, 1967.

- Lombardo Toledano, Vicente, El problema indígena, Ciudad de México, Sep-Setenta, 1973.

- Mariátegui, José Carlos, 7 ensayos sobre la realidad peruana, Lima, Biblioteca Amauta, 1976.

- Mariman Quemenado, Pablo, "El pueblo mapuche y la Reforma Agraria: una reforma entre cuatro contrarreformas", Revista anales de la Universidad de Chile, Séptima serie. No 12/2017.

- Marx, Karl, Elementos fundamentales para la crítica de la economía política (Grundrisse) 18571858, Ciudad de México, Siglo XXI, 2007.

- Manuel, Marzal, Historia de la Antropología Volumen I Primera parte: Antropología Indigenista, Quito, Abya-Yala, en coedición con Universidad Politécnica Salesiana, 1998.

- Melis, Antonio, Diccionario histórico-crítico del marxismo, Berlín, Instituto de Teoría Crítica de Berlín, 2004. Disponible en http:/ / dhcm.inkrit.org/cuestion-del-indio

- Molina Otárola, Raúl, “Geografías mapuches: territorios, política y desafíos en tiempos de cambio", Revista geográfica del sur, 3(1): 15-36, 2012.

- Nahuelpán, Héctor, “El sueño de la identidad latinoamericana o la búsqueda de lo propio en lo ajeno", Atenea n.495. Concepción, 2007.

- Órdenes Delgado, Mathias, "Conflicto mapuche-campesino en la Araucanía”, Izquierdas [En línea], 26 | enero 2016, Publicado el 01 enero 2016, consultado el 16 agosto 2019. URL: http://journals.openedition.org/izquierdas/637

- Pinto, Julio; Valdivia, Verónica y Artaza, Pablo, "Patria y clase en los albores de la identidad pampina (1860-1890)", Historia, Vol. 36, 275-332, Instituto de Historia Pontificia Universidad Católica de Chile, 2003.

- Pozas, Ricardo y Horcasitas, Isabel, Los indios en las clases sociales de México, La Habana, Casa de las Américas, 1971.

- Rabines, Eudocio, "El problema Indígena en América Latina" aparecido en "El trabajador Latinoamericano", Montevideo, marzo-abril, 1930, año II, N 30. Republicado en "Socialismo y Participación", CEDEP, Lima, Perú, 1980.

- Redondo, Jesús Ángel, “Las tomas de fundos en la provincia de Cautín (Chile), 1967-1973”, Cuadernos de historia (Santiago), (42), 2015.

- Ruíz Rodríguez, Carlos, “El pueblo mapuche y el gobierno de Salvador Allende y la Unidad Popular", Universidad de Santiago de Chile, Proyecto DICYT 03-0051 SM La cuestión 
mapuche: Chile, 1964-1973. Discursos y prácticas desde el Estado y la sociedad civil hacia las minorías étnicas, 2005.

- Saavedra, Alejandro, Los Mapuche en la sociedad chilena actual, Santiago, LOM, 2002.

- Samaniego, Augusto y Ruiz, Carlos, “Comunidad agraria y autonomías para el pueblo mapuche (1953-1972). Lipschutz y el hombre progresista: ¿Un marxismo liberal o innovador?", Revista de Historia Social y de las mentalidades" La construcción histórica del socialismo en Chile, Año VII, Volumen 2, Santiago, USACH, 2003.

- Sánchez, Adolfo, “El marxismo en América Latina”, Dialéctica, nº 19, 1988.

- Scaron, Pedro, "Introducción", en Karl Marx y Friedrich Engels, Materiales para la historia de América Latina, Córdoba, Cuadernos de Pasado y Presente 30, 1972.

- Skewes, Juan C., "Lipschutz, la bruja y la escena colonial", Pablo Neruda, Volodia Teitelboim, Oiga Poblete, Bernardo Berdichewsky, Zenta Kimene y Peter Krupnikov, José Manuel Lira, Roberto Morales y Juan Carlos Skewes, Alejandro Lipschutz Nueva Antología, CNCA-ICAL, Santiago, 2005.

- Jose Stalin, El Marxismo y la cuestión nacional, Barcelona, Anagrama, 1977.

- Thompson, Edward, La miseria de la teoría, Barcelona, Crítica, 1981.

- Téllez Lúgaro, Eduardo; Arancibia, Cristián; Canales, Juan; Ruit, Larisa de, Quinteros, Rodrigo y Quintupirray, Yuri, “El levantamiento del a Alto Bío- Bío y el Soviet y la República Araucana de 1934", Anales de la Universidad de Chile Sexta Serie, No13, agosto de 2001

- Ulianova, Olga, "Primeros Contactos entre el Partido Comunista de Chile y Komintern", Cuadernos de Historia número 18, Santiago, Departamento de Ciencias Históricas de la Universidad de Chile, diciembre 1998.

- Ulianova, Olga, "El levantamiento campesino de Lonquimay y la Internacional Comunista", Estudios Públicos número 89, Santiago, 2003.

- van Dijk, Teun A., “El análisis crítico del discurso”, Anthropos 186, (Barcelona), septiembreoctubre 1999, pp. 23-36.

- Wolf, Eric, Las luchas campesinas en el s. XX, Madrid, Siglo XXI, 1972.

- Wolf, Eric, Europa y la gente sin historia, Ciudad de México, Fondo de Cultura Económica, 1987.

\section{Medios de comunicación partidarios}

El Despertar de los Trabajadores (1912-1918 y 1921-1926)

Bandera Proletaria (1933)

Bandera Roja (1931-1934)

Justicia (1924-1927 y 1931-1936)

CTCH (1939)

El Siglo (1940-1948 y 1952-1973) 


\section{Siglas usadas}

Partido Comunista de Chile (PC)

Unidad Popular (UP)

Federación Obrera de Chile (FOCH)

Confederación de Trabajadores de Chile (CTCH)

Central Única de Trabajadores de Chile (CUT)

Asociación Nacional Indígena (ANI)

Frente de Acción Popular (FRAP)

Frente Único Proletario (FUP)

Unión de Repúblicas Socialistas Soviéticas (URSS)

Partido Obrero Socialista (POS) 